\title{
O empreendedorismo nas políticas públicas de trabalho e geração de renda
}

\author{
Entrepreneurship in public work and income generation policies \\ Erika Cordeiro do Rêgo Barros VALENTIM* \\ Juliane Feix PERUZZO**
}

\begin{abstract}
Resumo: O artigo tem por objetivo discutir a funcionalidade da ideologia empreendedora presente nas atuais políticas de geração de trabalho e renda no Brasil, apresentando seu alinhamento com as diretrizes de agências multilaterais como o Banco Mundial e o Fundo Monetário Internacional. No conjunto de tais políticas, evidenciamos o Programa Microempreendedor Individual (PMEI), problematizando algumas de suas implicações para a classe trabalhadora brasileira. O trabalho tem como fonte de pesquisa a revisão bibliográfica e documental e o levantamento de dados estatísticos. Nossa argumentação considera o empreendedorismo como uma das expressões da informalidade contemporânea e o PMEI enquanto instrumento de materialização da ideologia empreendedora e regressão dos direitos trabalhistas.

Palavras-Chave: Empreendedorismo. Políticas. Microempreendedor Individual.
\end{abstract}

\begin{abstract}
This article to discusses the functionality of entrepreneurial ideology present in current labor and income generation policies in Brazil, presenting its alignment with the guidelines of multilateral agencies such as the World Bank and the International Monetary Fund. Within such policies, we highlight the Individual Microentrepreneur Program (PMEI), problematizing some of its implications for the Brazilian working class. This work has been researched from a bibliographical and documentary review and the collection of statistical data. Our argument considers entrepreneurship as one of the expressions of contemporary informality and PMEI as an instrument for the materialization of entrepreneurial ideology and regression of labor rights.

Keywords: Entrepreneurship. Policies. Individual Micro-entrepreneur.
\end{abstract}

\section{Introdução}

Inscritas numa conjuntura marcada pelas determinações da reestruturação produtiva dos anos 1970 e pelos efeitos nefastos do neoliberalismo, as políticas mais recentes de geração de trabalho e renda no Brasil têm seguido os receituários das agências multilaterais de desenvolvimento econômico, no sentido de inovar as estratégias para o enfrentamento ao desemprego. Ganha centralidade nesse cenário, a criação de programas inspirados na lógica do desenvolvimento local, num processo de ressignificação do trabalho informal através das ideologias do empreendedorismo, do capital social, do empoderamento, da economia solidária, entre ou-

\footnotetext{
* Assistente Social. Mestre em Serviço Social pela Universidade Federal de Pernambuco (UFPE, Recife, Brasil). Assistente Social residente da Residência Multiprofissional na Rede de Atenção Psicossocial (RAPS), do município de Recife (PE). Av. Prof. Moraes Rego, 1235, Cidade Universitária, Recife (PE), CEP: 50670901. E-mail: <erikacrbbarros@gmail.com>. ORC ID: <http://orcid.org/oooo-0002-5603-1493>.

** Assistente Social. Doutora em Serviço Social. Docente da Graduação e Pós-Graduação do Curso de Serviço Social da Universidade Federal de Pernambuco (UFPE, Recife, Brasil). Av. Prof. Moraes Rego, 1235, Cidade Universitária, Recife (PE), CEP: 50670-901. E-mail:<peruzzo.juliane@gmail.com>. ORC ID: <http://orcid.org/oooo-0001-9834-0334>.
} 
tras, cujo sentido é o apagamento do ideário do trabalho estável, em prol da construção de formas flexíveis - precárias - de inserção no trabalho.

Na realidade brasileira, tais diretrizes têm sido implementadas, sobretudo, a partir dos anos 1990, com a criação de programas sociais de assistência social focalizada nos mais pobres, de prolongamento do tempo médio de qualificação do trabalhador, e na ênfase do empreendedorismo enquanto estratégia central para enfrentar o aumento dos índices de desocupação.

Para analisar essa problemática, este artigo está dividido em três seções. Na primeira, discutimos a funcionalidade da ideologia empreendedora no atual contexto do capitalismo, explicitando os motivos pelos quais tem se constituído como uma das principais ideologias do capital. Para tanto, resgatamos a perspectiva shumpeteriana de empreendedorismo, atentando para as alterações que o conceito tem experimentado na contemporaneidade. Na segunda, situamos a ideologia empreendedora enquanto estratégia central das políticas mais recentes de geração de trabalho e renda. Nesse sentido, discutimos as diretrizes do Banco Mundial (BM) e do Fundo Monetário Internacional (FMI) para as economias em desenvolvimento, particularizando a experiência brasileira no que diz respeito ao alinhamento de suas políticas com as propostas dessas agências multilaterais. Na última seção, apresentamos algumas reflexões sobre o Programa Microempreendedor Individual (PMEI), evidenciando seu papel de concretizador da ideologia empreendedora no cenário nacional. Por fim, discutimos sobre algumas das implicações do PMEI para a classe trabalhadora brasileira.

\section{A funcionalidade da ideologia empreendedora na contemporaneidade}

A efervescência da ideologia empreendedora no capitalismo atual pode ser explicada pela funcionalidade que suas características centrais adquirem no contexto de ampliação do desemprego estrutural e da necessidade de manutenção da hegemonia burguesa. Dois traços estruturais nos parecem fundamentar tal funcionalidade que vem sendo cumprida pelo empreendedorismo: (1) a negação de uma sociedade de classes e (2) a valorização do indivíduo e suas potencialidades, numa lógica de subjetivação do trabalhador ideal.

Fortemente inspiradas pelas ideias do economista Joseph Schumpeter1, as políticas de desenvolvimento formuladas a partir dos anos 1990, em nível mundial, estão centradas na ideia da inovação como a principal ferramenta do desenvolvimento, que possibilitaria criar as condições concorrenciais propícias à dinamização das economias e à ampliação do capital em geral. Para Schumpeter, o empreendedor é:

[...] O produtor que, via de regra, inicia a mudança econômica, e os consumidores, se necessário, são por ele 'educados'; eles são, por assim dizer, ensinados a desejar novas coisas, ou coisas que diferem de alguma forma daquelas que têm o hábito de consumir (SCHUMPETER, 1997, p. 76).

Através do processo que conceitua como destruição criadora - marcado pela substituição de antigos produtos e hábitos de consumo por inovações - Schumpeter afirma que a base

${ }^{1}$ Joseph Alois Schumpeter (1883-1850) foi um estudioso sobre o desenvolvimento econômico na escola do período neoclássico.

Argum., Vitória, v. 10, n. 1, p. 261-275, jan./abr. 2018. 
do processo de desenvolvimento econômico na sociedade capitalista são as inovações implementadas a partir da ação dos empreendedores. A criação de tais inovações resulta, de acordo com o autor, numa "[...] onda de investimentos de capital que ativa a economia, gerando a prosperidade e o aumento do nível de emprego" (SCHUMPETER, 1997, p. 11).

Conforme explica Schumpeter, o empreendedorismo se apresenta como uma função especial, para além da sociedade de classes e dos conflitos entre capital e trabalho. Tal função é definida pela capacidade de gerar inovações, riqueza e desenvolvimento no capitalismo, através da criação de bens de consumo, métodos de produção, abertura de novos mercados e fontes de matérias-primas, e a criação de novas organizações, indústrias ou monopólios. Para Schumpeter (1997), o empreendedor tanto pode ser um capitalista, quanto um trabalhador, desde que seja capaz de implementar tais inovações no sistema econômico. Assim, as desigualdades de classe são apreendidas, sob tal perspectiva, como diferenciações de comportamentos e aptidões individuais:

\begin{abstract}
A base em que se apoia o fenômeno da classe consiste nas diferenças individuais de aptidão. Entendemos, por isso, não diferenças num sentido absoluto, mas diferenças de aptidão em relação às funções que o meio torna 'socialmente necessárias' - em nosso sentido - num determinado momento, bem como em relação à liderança, dentro de linhas acordes com essas funções (SCHUMPETER, 1961, p. 187).
\end{abstract}

O segundo elemento que consideramos fundamental para a perfeita imbricação entre empreendedorismo e o atual contexto da sociedade capitalista - marcado pela lógica da acumulação flexível e da financeirização - é a valorização do indivíduo e suas potencialidades, isto é, a construção de um tipo ideal de indivíduo: o empreendedor. Este indivíduo é, segundo Schumpeter, o responsável pela realização de combinações novas, cuja função especial "[...] é privilégio de um tipo de pessoa muito menos numeroso do que todos os que têm a possibilidade objetiva de fazê-lo [...] são um tipo especial, e o seu comportamento um problema especial, a força motriz de um grande número de fenômenos significativos" (SCHUMPETER, 1997, p. 88).

Esse indivíduo dotado de aptidões e habilidades especiais para os negócios, sem medo de correr riscos, de inovar, conforme a definição de Schumpeter, se traduz nos nossos dias, como o trabalhador, que dispõe de um conjunto de competências a serem desenvolvidas: o otimismo, a autoconfiança, a flexibilidade, a coragem, a resiliência, a iniciativa, a próatividade, entre tantos outros atributos psicológicos que, se existem, precisam ser desenvolvidos, ou quando não existem, precisam ser buscados. Nessa direção, a Educação, dentre todos os aparelhos privados de hegemonia, tem sido um dos principais espaços de difusão da racionalidade capitalista, formando consensos em torno da ideologia empreendedora.

No âmbito dos modelos educacionais, ganha centralidade o estímulo à formação de competências empreendedoras enquanto condicionantes da empregabilidade, numa lógica de promoção das oportunidades para que o indivíduo consiga criar o seu próprio lugar no mercado - autoempregar-se - ao mesmo tempo em que tal ocupação não estaria fadada à referência do trabalho assalariado, do emprego formal, mas à geração de renda independente de sua forma. A solução para enfrentar o desemprego se desloca, nesse sentido, das condições econômicas para a esfera privada, individual. 
Nesse cenário de forte apelo ao empreendedorismo como a via para o enfrentamento ao desemprego, o empreendedor é apresentado como o indivíduo que incansavelmente não desiste de buscar as oportunidades até encontrá-las. Seu diferencial está na sua suposta capacidade de se esforçar o suficiente, de se interessar em conquistar seu sucesso financeiro. $\mathrm{O}$ sentido é de responsabilização individual pela empregabilidade, em que a persistência do empreendedor e sua coragem de tomar para si a responsabilidade de crescer na vida, sem culpar as condições objetivas - falta de apoio do Estado, de incentivo financeiro, condições econômicas e sociais - determinam a sua capacidade de se tornar um vencedor.

Com efeito, o resgate do conceito de empreendedorismo nos anos 1990 é acompanhado por novas abordagens, nas quais a questão da inovação (no seu sentido original), dá lugar a interpretações mais flexíveis, que consideram o empreendedor como alguém cujas ideias são transformadas em valores econômicos, independentemente do seu conteúdo inovador ou da criação de uma nova empresa (DUARTE, 2008). Ilustrativa dessa mudança substancial nas conceituações do empreendedorismo é a definição estabelecida pela organização de maior referência do empreendedorismo em nível internacional, a Global Entrepreneurship Monitor (GEM), que conceitua o empreendedorismo como: "[...] qualquer tentativa de criação de um novo negócio ou uma nova iniciativa, tal como emprego próprio, uma nova organização empresarial ou a expansão de um negócio existente, por um indivíduo, equipe de indivíduos, ou negócios estabelecidos" (GLOBAL ENTREPRENEURSHIP MONITOR, 2010, p. 4).

Tal definição expressa o movimento de fluidez, generalização e inespecificação do empreendedorismo enquanto conceito, uma vez que abarca uma série de categorias ocupacionais que não necessariamente carregam os elementos das concepções clássicas sobre o empreendedorismo: inovação, mudança, geração de riqueza, criação de novos produtos e até mesma a criação de uma empresa - o que contribui para um processo de elasticidade do conceito de empreendedorismo, ressignificando o trabalho autônomo, na maioria das vezes informal, enquanto atividade empreendedora.

É, pois, nesse cenário marcado pelos efeitos deletérios das medidas neoliberais - a ampliação do desemprego estrutural, da informalidade (acompanhada de suas novas expressões), a precarização das condições de vida e trabalho da classe trabalhadora - que o conceito de empreendedorismo experimenta um processo de alargamento, tanto na esfera das políticas públicas governamentais, quanto nas políticas empresariais privadas. Evidencia-se a perspectiva do empreendedorismo nas ações do Serviço Brasileiro de Apoio às Micro e Pequenas Empresas (SEBRAE) (parceiro histórico do Estado brasileiro); nas políticas governamentais de estímulo aos pequenos negócios e, preponderantemente, nas políticas públicas de geração de trabalho, emprego e renda.

\section{A centralidade do empreendedorismo nas políticas de geração de trabalho, emprego e renda no Brasil}

A partir dos anos 1990, pode-se identificar nos relatórios do Banco Mundial e do Fundo Monetário Internacional, os fundamentos que orientam as atuais políticas de trabalho, emprego e geração de renda no Brasil. Tais documentos apresentam, enquanto alternativas para as economias subdesenvolvidas, estratégias como: a abertura comercial ao investimento internacional; racionalização dos gastos estatais e privatização das empresas; a criação de pro-

Argum., Vitória, v. 10, n. 1, p. 261-275, jan./abr. 2018. 
gramas de assistência social voltados às parcelas mais pobres das populações e executados por Organizações Não Governamentais (ONGs); e o investimento na Educação, na qualificação dos trabalhadores - considerada a mediação central entre produtividade e crescimento, e o caminho para fazer crescer a confiança do indivíduo e sua capacidade de criar e inovar, multiplicando suas chances de melhorar seu padrão de vida, já que "[...] no clima dinâmico e incerto do progresso tecnológico, os trabalhadores mais instruídos levam grande vantagem" (BANCO MUNDIAL, 1991, p. 64).

A implantação dessas medidas nas políticas brasileiras durante a década de 90 do século XX resultou na criação dos primeiros programas de transferência de renda: o Programa de Garantia de Renda Mínima (PGRM), e o Programa Comunidade Solidária.2 Esses programas, sob a lógica da focalização e da seletividade, tinham como finalidade aumentar os índices de consumo da população e reduzir a extrema pobreza. No que se refere às políticas de trabalho, o alinhamento com as propostas do BM se dá de forma contraditória à medida em que se observam alguns avanços ligados à proteção básica do trabalhador e à qualificação profissional (ainda que permeada por suas múltiplas contradições), ao mesmo tempo que imprime um sentido de regressão na legislação trabalhista e consequentemente nas relações de trabalho.

Enquanto expressões desse movimento, há a criação do seguro desemprego e do Fundo de Amparo ao Trabalhador (FAT), ambos na década de 1990. Na mesma década, é instituído o Plano Nacional de Qualificação do Trabalhador (PLANFOR), visando à qualificação e requalificação dos setores tradicionalmente de baixa escolaridade, com o objetivo de elevar o nível de empregabilidade desses trabalhadores. Tais programas são acompanhados pela ampliação dos contratos atípicos de trabalho, a exemplo dos contratos por prazo determinado - previstos na lei no 9.601, de 21 de janeiro de 1998 - corroborando para a instalação de mecanismos de flexibilidade e desregulamentação trabalhista.

Na conjuntura dos anos 200o, a partir da publicação do Relatório do Banco Mundial Equidade e Desenvolvimento (BANCO MUNDIAL, 2006) - documento que passa a ser a principal referência para as políticas de trabalho nas economias periféricas - são apresentadas novas diretrizes, fundadas, essencialmente, na suposta necessidade de equilibrar flexibilidade trabalhista com proteção social, cujo objetivo seria o de reduzir o desemprego e oferecer "[...] condições iguais de emprego ao maior número possível de trabalhadores" (BANCO MUNDIAL, 2006, p. 16). Segundo o Relatório, há uma rigidez e formalização muito extensas na legislação trabalhista de países como o Brasil, e menor no que se refere ao setor informal. Essa combinação implica numa proteção ineficaz para os trabalhadores mais pobres. Argumenta-se que, mesmo garantindo uma maior estabilidade aos trabalhadores, o trabalho formal "[...] geralmente representa um mau negócio para os próprios trabalhadores, como ocorre quando os sistemas de seguro social relativos ao trabalho são ineficazes" (BANCO MUNDIAL, 2006, p. 16).

Diante disso, caberia a estas economias o estímulo ao trabalho informal, que nos países em desenvolvimento desempenha um papel fundamental na geração de emprego e renda. Para além da informalidade, as orientações das agências multilaterais incentivam a qualificação e requalificação profissional, com cursos técnicos gratuitos ofe-

${ }_{2}^{2}$ Programas implantados no governo de Fernando Henrique Cardoso (1995 a 2002).

Argum., Vitória, v. 10, n. 1, p. 261-275, jan./abr. 2018. 
recidos à população de baixa renda. Neste sentido, podemos perceber que a superação do desemprego encontra-se alicerçada na ideia de fortalecimento das capacidades individuais e não dinâmica da acumulação capitalista (OLIVEIRA, 2015, p. 5).

Nesse sentido, são elencadas duas diretrizes para a conciliação entre desenvolvimento e equidade nas economias em desenvolvimento: 1 - Garantir a efetivação dos direitos mais fundamentais do trabalho, como a extinção do trabalho escravo e forçado, o trabalho infantil, e demais formas de trabalho que desrespeitem os direitos humanos; 2 - Uma reavaliação das legislações trabalhistas, no sentido de flexibilizar as políticas de trabalho como necessidade da reestruturação, "[...] tão fundamental para o crescimento econômico e a criação de empregos" (BANCO MUNDIAL, 2006, p. 16). Ainda em seu relatório publicado entre os anos 1998-1999, o FMI aponta como estratégia para as economias em desenvolvimento, a necessidade de "[...] melhorar a flexibilidade dos mercados de trabalho e de produtos, a fim de reduzir o elevado nível de desemprego estrutural" (FUNDO MONETÁRIO INTERNACIONAL, 1999, p. 63, tradução nossa). Desse modo, entende-se que há uma excessiva proteção ao trabalhador, que termina por onerar a contratação massiva de trabalhadores, aumentando os níveis de desocupação. Afirma-se a necessidade de flexibilizar as legislações relativas ao trabalho formal e regulamentar o trabalho informal.

Para a correção desses problemas, o BM propõe a estratégia de combinar esquemas de seguro desemprego e esquemas de emprego de baixa remuneração, ou seja, a redução real dos salários (o que garantiria o aumento dos níveis de emprego). As estratégias apresentadas revelam, nesse sentido, as tentativas de regressão dos direitos do trabalho, a clara centralidade - naturalização - do trabalho informal e um grande investimento em políticas e programas voltados para geração de trabalho e renda. É, pois, nesse sentido que, adequada aos receituários neoliberais, a ideologia empreendedora adquire centralidade nas políticas de geração de trabalho e renda e nas políticas de flexibilização e desregulamentação dos direitos trabalhistas.

Como resultado desse processo, a imagem social do trabalho autônomo, informal, deslocase, progressivamente, de uma identificação negativa, precária, periférica, destinada apenas aos mais pobres e fadada à subsistência pessoal, para adquirir um viés participativo, positivo, de liberdade, de realização pessoal, substituindo o ideário do trabalho estável, de carteira assinada, pela ideia de que qualquer indivíduo pode ter o seu próprio negócio e tornar-se um empreendedor de sucesso.

Ainda no que se refere ao alinhamento das políticas de trabalho no Brasil, com as diretrizes do BM e FMI, na entrada dos anos 2000, observamos que durante os governos petistas Lula (2003-2011) e Dilma (2011-2016) houve a continuidade da adesão ao receituário dessas agências multilaterais, de modo a modificar, em alguns aspectos, os programas instituídos no governo de Fernando Henrique Cardoso (FHC) e implementar outros programas, porém, seguindo as mesmas tendências até então desenhadas.

Dessa forma, observa-se a expansão da política de assistência social, cujo carro-chefe foi o Programa Bolsa Família e a reformulação e criação de programas educacionais e de qualificação do trabalhador, como o Programa Nacional de Estímulo ao Primeiro Emprego (2003); o Programa Economia Solidária em Desenvolvimento (2003); o Programa Universidade para

Argum., Vitória, v. 10, n. 1, p. 261-275, jan./abr. 2018. 
Todos (PROUNI) (2004); o Programa Nacional de Microcrédito Produtivo Orientado (2005); o Programa Nacional de Inclusão de Jovens (PROJOVEM) (2005); o Programa Microempreendedor Individual (PMEI) (2008), e a criação do Programa Nacional de Acesso ao Ensino Técnico e Emprego (PRONATEC) (2011), com o objetivo de estimular a articulação entre a política de educação profissional e as políticas de geração de renda, através da implantação de escolas técnicas, institutos federais de tecnologia, cursos técnicos gratuitos em parceria com o Sistema S e a concessão de bolsas-formação.

Não completados dois meses após a sua chegada ao poder, o governo Temer anunciou o aumento de $12,5 \%$ dos benefícios do principal programa de assistência social do Brasil - o Bolsa Família - (uma vez que a última correção dos valores havia sido feita há dois anos), ao mesmo tempo em que o Ministério do Desenvolvimento Social realizou o maior pente fino da história do programa, cancelando 469 mil benefícios, 8\% do total de beneficiários do programa, o que equivale a 13,9 bilhões (BRASIL, 2016; O QUE MUDOU..., 2016).

No âmbito das políticas de geração de renda direcionadas ao empreendedorismo, o governo Temer criou em janeiro de 2017 o Programa Empreender Mais Simples, em parceria com o Sebrae e o Banco do Brasil, com a finalidade de reduzir a burocracia e orientar o acesso ao crédito dos microempreendedores, apontado como uma melhoria do Programa Microempreendedor Individual e do Simples Nacional. Pari passu à centralidade do empreendedorismo enquanto a principal estratégia de geração de trabalho e renda no Brasil, assiste-se, no momento atual, ao discurso da suposta necessidade de modernizar as relações trabalhistas, como prioridade absoluta do governo Temer, demarcando, assim, o fim da Consolidação das Leis do Trabalho (CLT).

Como podemos observar, as políticas de trabalho e geração de renda nos governos Lula, Dilma e Temer - sob o signo da inclusão produtiva - não só deram continuidade às propostas do BM e à lógica dos programas criados no governo FHC, como os ampliaram. Ao invés de políticas concretas de trabalho, e de proteção ao trabalhador, observa-se a criação de programas paliativos, cujo sentido é aumentar o tempo de formação do trabalhador, em nome do discurso da qualificação; ofertar melhores condições para o consumo, via transferência de renda aos comprovadamente mais pobres e estimular o empreendedorismo, debitando aos trabalhadores, em nome de aproveitar as capacidades e oportunidades, a responsabilização pela sua empregabilidade, ou melhor, pela sua sobrevivência, como poderemos evidenciar no Programa do Microempreendedor Individual, discutido a seguir.

\section{O Programa Microempreendedor Individual: reflexões sobre suas implicações para a classe trabalhadora}

A construção da cultura empreendedora no Brasil tem sido acompanhada de crescentes índices de desemprego e informalidade, contabilizando, em 2016, um total de 52 milhões de empreendedores entre 18 e 64 anos, ao mesmo tempo que registra, em 2017, 13,2 milhões de pessoas desocupadas e 10,7 milhões de trabalhadores informais (GLOBAL ENTREPRENEURSHIP MONITOR, 2016; INSTITUTO BRASILEIRO DE GEOGRAFIA E ESTATÍSTICA, 2017.

Em resposta ao fenômeno do trabalho informal, o Estado tem criado programas e projetos de fomento à formalização do trabalho, direcionados a empreendedores informais. Entre tais

Argum., Vitória, v. 10, n. 1, p. 261-275, jan./abr. 2018. 
iniciativas está o PMEI, instituído em nível federal no ano de 2008, representando hoje uma das principais estratégias de enfrentamento ao desemprego e à informalidade no país.

Criado através da Lei Complementar no 128/2008, o PMEI reconhece como Microempreendedor Individual (MEI) o indivíduo que trabalha por conta própria e se legaliza como pequeno empresário. O faturamento máximo anual do MEI é de R\$60.0oo,oo, não sendo permitida a sua participação como sócio ou titular de outra empresa. As vantagens oferecidas para os empreendedores que participam do programa compreendem o acesso a benefícios como: o registro no Cadastro Nacional de Pessoas Jurídicas (CNPJ), facilitando a abertura de contas, acesso a empréstimos, emissão de notas fiscais; a simplificação dos impostos federais a partir do pagamento fixo mensal de valores que variam de $\mathrm{R} \$ 47,85$ à $\mathrm{R} \$ 52,85$, acrescidos das taxas estaduais /municipais de cada localidade; e os benefícios de auxílio maternidade, auxílio doença, auxílio reclusão e aposentadoria.

O PMEI se direciona para um público de trabalhadores por conta própria, que, diferente das microempresas e empresas de pequeno porte, tem a quantidade de funcionários limitada a apenas 1 (um). Em contrapartida, o microempresário “[...] é um tipo societário, constituído por apenas uma pessoa, que exerce uma atividade econômica organizada”, e que pode empregar quantos trabalhadores quiser (SERVIÇO BRASILEIRO DE APOIO ÀS MICRO E PEQUENAS EMPRESAS, 2017b p. 1).

Nesse sentido, a diferença fundamental entre o microempreendedor individual e o microempresário (definido pelo Estatuto Nacional da Microempresa e da Empresa de Pequeno Portez) é o rendimento, que define o MEI numa escala econômica e social abaixo da figura do microempresário. Acerca disso, Jorge (2015) considera que o termo MEI, em relação ao termo microempresário, é associado pelos microempreendedores individuais à palavra meio, denotando o sentido de meio empresário, meio empreendedor. Ou ainda, meio capitalista renovando as ideias de Schumpeter (1997), que afirmam o empreendedor como um indivíduo que se coloca para além do pertencimento de uma classe social.

Como sabemos, o trabalho autônomo, ou por conta própria é historicamente associado à economia informal, como uma de suas principais expressões. A regulamentação proposta pelo PMEI ao trabalhador autônomo, confere, portanto, a ideia de transição da informalidade para a formalidade, tornando possível a generalização da modalidade de trabalho autônomo formal, ou, em nossa análise, a regulamentação da informalidade, que na maioria das vezes não implica a sua superação concreta.

Desde sua criação, o PMEI vem registrando um crescimento substantivo de adesões, chegando há mais de 7 milhões de empreendedores optantes, após oito anos de existência. De acordo com o Sebrae, o IBGE define o trabalhador por conta própria como "[...] a pessoa que trabalha explorando seu próprio empreendimento, sozinha ou com sócio, sem ter empregado e contando, ou não, com a ajuda de trabalhador familiar auxiliar" (SERVIÇO BRASILEIRO DE APOIO ÀS MICRO E PEQUENAS EMPRESAS, 2016a, p. 20). A grande maioria dos MEIs se enquadra na condição de trabalhadores por conta-própria, uma vez que geralmente não têm empregados, ou quando têm, estes são contratados de forma irregular - informal.

3Lei Complementar $\mathrm{n}^{\circ}$ 123, de 14 de dezembro de 2006.

Argum., Vitória, v. 10, n. 1, p. 261-275, jan./abr. 2018. 
Dados da Secretaria Especial da Micro e Pequena Empresa (2016) demostram, também, que os MEIs foram responsáveis por 8o\% dos empreendimentos registrados em 2015, e pela maioria das empresas criadas nos últimos anos, alcançando, em 2016, o aumento de $21 \%$ das formalizações.

Gráfico 1 - Evolução do número de MEIs formalizados no Brasil (2009 - 2017)

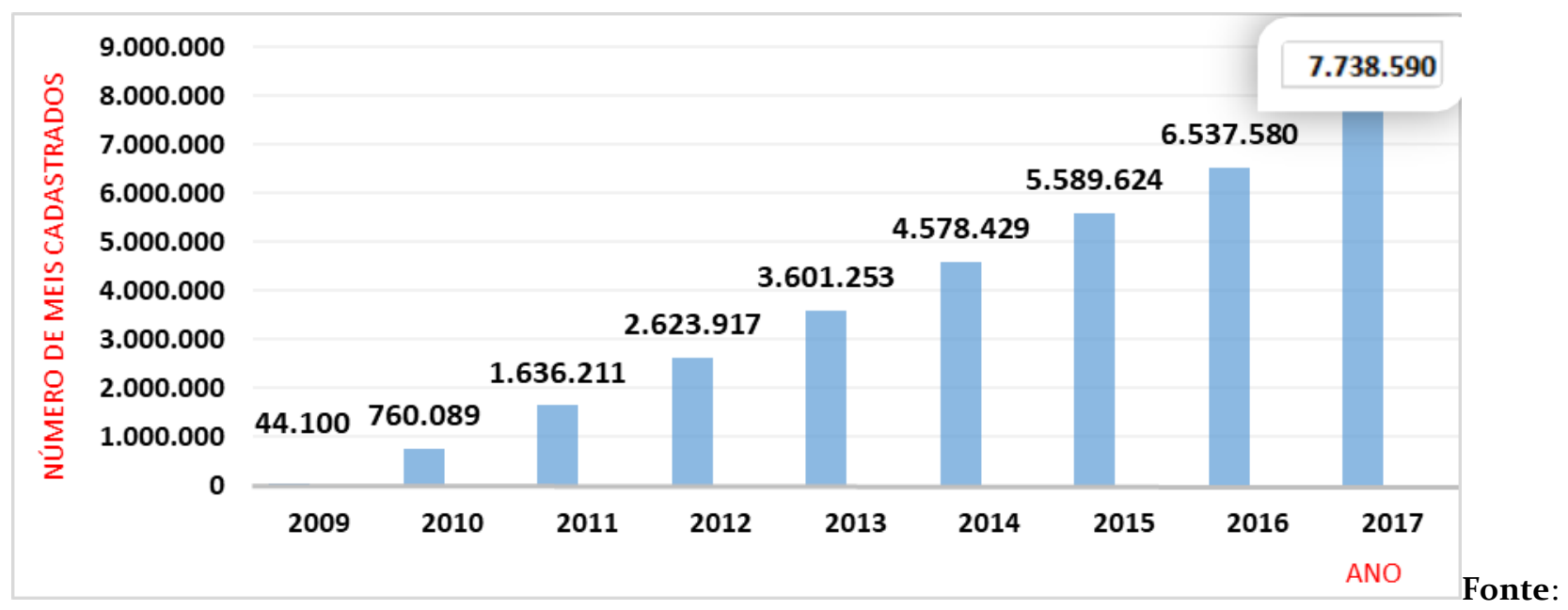

Fonte: Portal do Empreendedor - MEI (2017). Elaboração própria.

Ainda que as estatísticas sinalizem a progressão de MEIs registrados, observa-se uma enorme distância entre o índice de MEIs (7 milhões) e o índice de trabalhadores por conta própria no Brasil (22,7 milhões), o que revela a reprodução da informalidade em grande escala mesmo diante da implantação do programa (PORTAL DO EMPREENDEDOR - MEI, 2017; INSTITUTO BRASILEIRO DE GEOGRAFIA E ESTATÍSTICA, 2017).

Outro aspecto importante a ser destacado é a distribuição regional de MEIs formalizados no Brasil. Dentre as cinco regiões, o Sudeste $(51,6 \%)$ e o Nordeste $(19,1 \%)$ apresentam os maiores índices de optantes, seguidos pela região Sul $(15,2 \%)$, Centro-Oeste $(8,7 \%)$ e Norte $(5,4 \%)$. Sobretudo no que se refere ao Nordeste $-\mathbf{2}^{\mathbf{a}}$ região com o maior número de MEIs os pequenos negócios se limitam apenas à subsistência básica do empreendedor e de sua família. Vale destacar que são justamente nas regiões em que o MEI apresenta os maiores índices de optantes em, que se observam os maiores índices de demissões - o Sudeste (com 7.553.839 trabalhadores demitidos), o Sul (3.013.723) e o Nordeste (2.059.993) lideraram o número de demissões no ano de 2017, seguidos pelas Centro-Oeste (1.402.154) e Norte (627.022) (SERVIÇO BRASILEIRO DE APOIO ÀS MICRO E PEQUENAS EMPRESAS, 2017a; MINISTÉRIO DO TRABABALHO, 2017).

De acordo com uma pesquisa realizada pelo Sebrae (2017a) sobre o perfil dos MEIs, os principais motivos para a adesão ao programa, apontados pelos microempreendedores individuais, são: ter uma empresa formalizada; ter acesso aos benefícios da Previdência Social, como o auxílio-doença, salário-maternidade, aposentadoria, pensão e auxílio reclusão, garantidos através da formalização via PMEI e a possibilidade de emitir nota fiscal. Ainda sobre o perfil dos MEIs, a pesquisa aponta que $33 \%$ tem de 30 a 39 anos de idade, e $68 \%$ possuem nível médio e técnico. A maior parte das atividades realizadas estão relacionadas ao comércio $(37,4 \%)$ e serviços $(37,2 \%)$. No que se refere às ocupações anteriores do microempreende-

Argum., Vitória, v. 10, n. 1, p. 261-275, jan./abr. 2018. 
dor, a pesquisa aponta que a maior parte é egressa do emprego formal (50\%), seguida pelo emprego informal (23\%), revelando que (76\%), ou (3/4) dos MEIs, não tem experiência prévia como empreendedor.

Acerca da formalização do trabalhador a partir da inserção no PMEI, cabe pontuar que, na contemporaneidade, os limites entre o formal e o informal estão cada vez mais estreitados. A informalidade, no contexto atual, tem se complexificado, a ponto de ser cada vez mais difícil diferenciar as ocupações formais das informais. Concordamos com a análise de Tavares (2002) ao afirmar que:

[...] O trabalho informal não comporta apenas ocupações excluídas do trabalho coletivo, e menos ainda, que se restringe às atividades de estrita sobrevivência. Toda relação entre capital e trabalho na qual a compra da força de trabalho é dissimulada por mecanismos que descaracterizam a condição formal de assalariamento, dando a impressão de uma relação de compra e venda de mercadorias, consubstancia trabalho informal, embora certas atividades desse conjunto heterogêneo divirjam no comportamento. Como as referências conhecidas para regular o emprego estão perdendo sua pertinência, a tipologia formal/informal se torna insustentável, a não ser que se tenha um conceito de formalidade, cuja base para ser trabalhador formal seja tão-somente estar diretamente empregado por meios de produção tipicamente capitalistas, embora submetido à mesma desproteção social que o trabalhador informal (TAVARES, 2002, p. 52).

Nesse sentido, compreender as fronteiras entre o formal e informal exige ir muito além da concepção liberal setorialista, fundada no conceito de setor informal, e considerar que o trabalho informal no capitalismo atual, torna-se "[...] intersticial" (TAVARES, 2002, p. 52). Sendo assim, não é a relação de deslocamento físico que determina o que é trabalho produtivo e o que é trabalho improdutivo, mas, dentro ou fora da fábrica, o trabalho produtivo continua sendo trabalho produtivo, determinado pela produção de mais valia do trabalhador para o capital. Como também, nem todo o tipo de regulamentação jurídica relativa à regulação da relação capital e trabalho implica a inexistência de informalidade.

Conforme dados de uma pesquisa realizada pela Global Entrepreneurship Monitor (GEM) no ano de 2016, 71\% dos empreendedores brasileiros iniciais4 possuem renda familiar entre 1 a 3 salários mínimos, faixa salarial classificada pelo IBGE como classe "D”, considerada baixa, apenas superior a classe "E". Cabe destacar que essa modalidade de empreendedores — os iniciais - constituem a maior parcela dos empreendedores brasileiros, cuja taxa é de $(19,6)$ (GLOBAL ENTREPRENEURSHIP MONITOR, 2016).

No estudo de Mattos e Pereira (2016), constatou-se que, apesar do aumento das taxas de formalização, o PMEI se caracteriza, na prática, como um programa marcado pela precariedade dos serviços de apoio contábil e assessoria aos empreendedores informais, no sentido de orientar sobre a formalização, cujos resultados apontam para a permanência dos MEIs em condições de trabalho precárias. Há também, na análise das autoras, uma tendência de fusão entre o formal e informal, ocasionada pelos critérios do programa no que se refere ao valor

\footnotetext{
4 Segundo a GEM, os empreendedores iniciais são aqueles que administram e são proprietários de um novo negócio que pagou salários, gerou pró-labores ou qualquer outra forma de remuneração aos proprietários por mais de três e menos de 42 meses, ou que ainda não realizou tais remunerações (GLOBAL ENTREPRENEURSHIP MONITOR, 2016).
}

Argum., Vitória, v. 10, n. 1, p. 261-275, jan./abr. 2018. 
máximo de faturamento anual e o limite de contratação de apenas um empregado, levando os MEIs a burlar esses requisitos (MATOS; PEREIRA, 2016).

Outra expressão das contradições presentes nessa política é o aumento do índice de inadimplência dos Microempreendedores Individuais, que, de acordo com a Receita Federal, somou 3,7 milhões de MEIs inadimplentes em julho de 2016. Historicamente elevada, a taxa de inadimplência em 2016 é a maior desde a criação do programa, passando de 55,5\% no final de 2015, para 59,08\% em julho de 2016. De acordo com as estatísticas, 6 em cada 10 microempreendedores estão em dívida com os tributos devidos. A causa apontada para a elevação da inadimplência dos MEIs é a crise econômica, que tem levado à falência muitos microempreendedores (SERVIÇO BRASILEIRO DE APOIO ÀS MICRO E PEQUENAS EMPRESAS, 2016b). Diante disso, Silva e Teixeira (2015) consideram que:

[...] Na verdade, a política de formalização pelo microempreendedorismo individual se configura enquanto novo fetiche de enfrentamento à desigualdade social, na medida em que se transforma em foco central de promoção da segurança no trabalho [...] e na proteção social. Pelo que se percebe, essa política de formalização representa mais uma estratégia de dominação política pelo atendimento de algumas necessidades objetivas da classe trabalhadora, integrando-as à lógica reprodutiva do capital (SILVA; TEIXEIRA, 2015, p. 629).

A inadimplência da contribuição resulta, para os MEIs, na perda de todos os benefícios que compõem a cobertura previdenciária, ou seja, caso necessitem de algum benefício não programado, como auxílio doença, pensão por morte ou salário maternidade, por exemplo, poderão não ter direito a acessá-los. Além desses prejuízos, no momento de recolhimento das contribuições atrasadas, o trabalhador terá que calcular os valores acrescidos de multa e juros. Assim, aquilo que é propagado como vantagens para o trabalhador, ao se formalizar como MEI, pode se configurar como custos e encargos de responsabilidade exclusiva do próprio trabalhador.

\section{Conclusão}

Um balanço geral das políticas públicas de trabalho e geração de renda implementadas nos governos Lula, Dilma e Temer, nos permite afirmar uma linha contígua de programas alicerçados nas propostas de assistência social focalizada, qualificação profissional estendida como forma de ocupação dos jovens face ao desemprego, visando ao adiamento de sua entrada no mercado de trabalho - e o empreendedorismo como o novo fetiche da política de trabalho. Ao nosso ver, a centralidade da geração de renda, da inclusão produtiva em detrimento do trabalho formal, de carteira assinada, revela, na realidade, a ausência de uma política de trabalho no Brasil. A análise desses programas demonstra o esforço em retirar a centralidade do trabalho formal, do reconhecimento dos direitos da classe trabalhadora, em favor de alternativas criativas de geração de renda. Parece-nos que o trabalho cada vez mais desaparece do vocabulário das políticas sociais brasileiras, e as alternativas / políticas de geração de renda, ganham cada vez mais destaque.

No nosso entendimento, a migração do trabalhador autônomo da informalidade para o trabalho formal, através do PMEI, consiste num processo de regulamentação da economia informal, uma vez que, ao se formalizar enquanto MEI, o trabalhador autônomo acessa os di-

Argum., Vitória, v. 10, n. 1, p. 261-275, jan./abr. 2018. 
reitos trabalhistas, próprios do núcleo da formalidade, de forma bastante precária e condicionada. A respeito disso, consideramos que o empreendedorismo constitui uma das formas de ser da informalidade contemporânea, que revela o grau de complexificação do fenômeno do trabalho informal e do próprio desafio de reconstrução do conceito de informalidade, face às mudanças em curso.

A ideologia empreendedora torna-se extremamente funcional ao capitalismo atual, uma vez que produz um apagamento dos conflitos entre capital e trabalho e das contradições desse modo de produção. Essa ideologia, oculta o debate do desemprego enquanto condição estrutural do capitalismo e constrói uma naturalização do trabalho informal, precário, transformando, no âmbito da aparência, as relações entre capital e trabalho, empregador e empregado, em relações entre empreendedores (VALENTIM; PERUZZO, 2017).

Ao nosso ver, o PMEI concretiza a difusão do empreendedorismo no cenário nacional, se apresentando enquanto a alternativa para o enfrentamento ao desemprego e à informalidade, e promovendo uma determinada modalidade de proteção social que se revela como mínima e precária, orientada segundo a lógica do mercado, cujo sentido corresponde à redução substantiva dos direitos dos trabalhadores-empreendedores.

No contexto atual de retrocesso dos direitos do trabalho e da Previdência Social, no qual as perdas da classe trabalhadora são apresentadas como um processo de modernização trabalhista, há uma tendência de ampliação de adesões ao PMEI e de reconfiguração do programa a partir do reconhecimento legal da terceirização irrestrita, que agora não se restringe às atividades-meio, abarcando também as atividades-fim. Assim, qualquer atividade de uma empresa poderá ser desempenhada por um trabalhador pejotizado, um MEI.

Contudo, tal lógica perversa se depara com suas próprias limitações, como, por exemplo, os impactos negativos para as contas públicas, já que acarretará a queda da receita da União a partir da transformação de um grande número de trabalhadores com carteira assinada em Pessoas Jurídicas, ou MEIs, "[...] cujas alíquotas incidentes sobre o valor mínimo são 50\% menores que as praticadas num vínculo trabalhista registrado em carteira” (FAGNANI, 2017, não paginado).

Nesse sentido, se revela a funcionalidade do PMEI ao capital, no contexto de exacerbação da contrarreforma trabalhista, uma vez que se mostra alinhado ao receituário de negação aos direitos básicos do trabalhador, e, ao mesmo tempo, configura-se como uma das alternativas de sobrevivência à classe trabalhadora brasileira, que vivencia o aumento do desemprego, o distanciamento progressivo de qualquer expectativa em relação à aposentadoria, e a necessidade de complementação de renda a partir do aumento do trabalho parcial.

Assim, dado o seu caráter instável - uma vez que a qualquer tempo o pequeno negócio pode vir a falir - a cobertura previdenciária dos MEIs não se realiza em sua integralidade, permanecendo como incompleta e instável. A ponte que o PMEI constrói entre o Trabalho e a Previdência tem suas bases ameaçadas, a partir do momento que o trabalhador não mais conseguir pagar os impostos devidos, de modo a perder, imediatamente todos os direitos a que teria acesso, caindo novamente no abismo da informalidade.

Argum., Vitória, v. 10, n. 1, p. 261-275, jan./abr. 2018. 
Em sintonia com os receituários propostos pelas agências multilaterais como o BM e o FMI, o PMEI se constitui como um programa que afrouxa, adapta e elimina importantes direitos do trabalho. Implica, dessa forma, em drásticos efeitos para a classe trabalhadora brasileira, que, para além da perda concreta e imediata de vários direitos trabalhistas, experimenta o seu não reconhecimento enquanto classe e, portanto, como sujeitos de direitos trabalhistas.

\section{Referências}

BANCO MUNDIAL. Relatório sobre o desenvolvimento Mundial 1991: o desafio do desenvolvimento. Fundação Getúlio Vargas: Rio de Janeiro, 1991.

BANCO MUNDIAL. Relatório Equidade e Desenvolvimento 2oo6: equidade e desenvolvimento: visão geral. Washington (D.C.), (C)2005. Disponível em:

<http://siteresources.worldbank.org/INTWDR2006/Resources/477383-

1127230817535/o821364154.pdf>. Acesso em: 5 jan. 2017.

BRASIL. Bolsa Família começa a ser pago com reajuste de 12,5\%. Cidadania e Justiça. 19 jul. 2016. Disponível em: <http://www.brasil.gov.br/cidadania-e-justica/2016/o7/bolsafamilia-comeca-a-ser-pago-com-reajuste-de-12-5>. Acesso em: 10 jul. 2017.

DUARTE, Rosa Maria Tavares. Determinantes de Empreendedorismo: o papel dos BIC. 2008. Dissertação (Mestrado em Inovação e Empreendedorismo Tecnológico)- Faculdade de Engenharia Universidade do Porto, Lisboa, 2008.

FAGNANI, Eduardo. As reformas de Temer podem quebrar a Previdência. Carta Capital, São Paulo, 4 abr. 2016. Economia. Disponível em:

<https://www.cartacapital.com.br/economia/as-reformas-de-temer-podem-quebrar-aprevidencia>. Acesso em: 10 mai. 2017.

FUNDO MONETÁRIO INTERNACIONAL. Evolución de la crisis en las economías de mercados emergentes. In: Informe Anual del Directorio Ejecutivo Correspondiente al Ejercicio Cerrado el 30 de Abril de 1999. Washington (D.C.), Set. 1999. Disponível em: <http://www.imf.org/es/Publications/AREB/Issues/2016/12/31/Annual-Report-of-theExecutive-Board-for-the-Financial-Year-Ended-April-30-1999>. Acesso em: 10 abr. 2017.

GLOBAL ENTREPRENEURSHIP MONITOR. Empreendedorismo no Brasil: 2016. Brasília (DF), 2016. Disponível em:

<https://www.sebrae.com.br/Sebrae/Portal\%2oSebrae/Anexos/GEM\%2oNacional\%2o\%2oweb.pdf>. Acesso em: 10 abr. 2017.

GLOBAL ENTREPRENEURSHIP MONITOR. Estudo sobre o Empreendedorismo. Lisboa, 2010. Disponível em:

<http://www.empreender.aip.pt/irj/go/km/docs/sitemanager/www_empreender_aip_pt/doc umentos/pt/barometro/destaque/GEM_Portugal_Final.pdf >. Acesso em: 10 abr. 2017.

INSTITUTO BRASILEIRO DE GEOGRAFIA E ESTATÍSTICA. Indicadores IBGE: Pesquisa Nacional por Amostra de Domicílios Contínua - Pnad Contínua - Principais destaques da evolução do mercado de trabalho no Brasil 2012-2017. Brasília (DF), 2017. Disponível em:

Argum., Vitória, v. 10, n. 1, p. 261-275, jan./abr. 2018. 
<ftp://ftp.ibge.gov.br/Trabalho_e_Rendimento/Pesquisa_Nacional_por_Amostra_de_Domic ili-

os_continua/Principais_destaques_PNAD_continua_2012_2017/PNAD_continua_retrospecti va_2012_2017.pdf>. Acesso em: 12 mar. 2018.

JORGE, Carolina Guedes Camelo de. A representação social do microempreendedor individual na publicidade do Sebrae. 2015. Dissertação (Mestrado em Comunicação)Programa de Pós-Graduação em Comunicação da Universidade de Brasília, Brasília (DF), 2015 .

MATTOS, Fernanda Gomes; PEREIRA, Juliana Nunes. Neodesenvolvimentismo, informalidade e nova morfologia do trabalho: reflexões sobre a precarização do trabalho no Brasil. Áskesis, Florianopólis, v. 5, n. 1, p. 59-72, jan./jun.2016.

MINISTÉRIO DO TRABALHO. Programa de Disseminação das Estatísticas do Trabalho. Cadastro Geral de Empregados e Desempregados - CAGED de dezembro de 2017. Brasília (DF), 2017. Disponível em: <http://pdet.mte.gov.br/caged/caged-2017/cageddezembro-2017>. Acesso em: 12 mar. 2018.

OLIVEIRA, Ednéia Alves. A política de emprego no Brasil: geração de renda ou reinserção no mercado de trabalho. Revista online Libertas, v. 15, n. 1, 2015. Disponível em:

<https://libertas.ufff.emnuvens.com.br/libertas/issue/view/26o>. Acesso em: 2 jan. 2017.

O QUE MUDOU com Temer nos programas sociais como o Bolsa Família? BBC Brasil. Brasília (DF), 19 nov. 2016. Disponível em: <http://www.bbc.com/portuguese/brasil-37991062>. Acesso em: 10 jul. 2017.

PORTAL DO EMPREENDEDOR-MEI. Brasília (DF), 2017. Inscritos totais - Estatísticas. Disponível em: < http://www.portaldoempreendedor.gov.br/estatisticas>. Acesso em: o1 jan. 2018.

SCHUMPETER, Josepy Alois. Capitalismo, Socialismo e Democracia. Rio de Janeiro: Fundo de Cultura, 1961.

SCHUMPETER, Josepy Alois. Teoria do desenvolvimento econômico: uma investigação sobre lucros, capital, crédito, juro e o ciclo econômico. São Paulo: Nova Cultural, 1997.

SECRETARIA ESPECIAL DA MICRO E PEQUENA EMPRESA. MEI: 21\% de aumento na formalização em um ano. Brasília, 2016. Disponível em:

<http://www.sempe.mdic.gov.br/clientes/smpe/smpe/noticias/mei-21-de-aumento-naformalizacao-em-um-ano> Acesso em: 12 mar. 2018.

SERVIÇO BRASILEIRO DE APOIO ÀS MICRO E PEQUENAS EMPRESAS. Perfil do Microempreendedor Individual 2015. Brasília (DF), 2016a. Disponível em: <http://www.sebrae.com.br/Sebrae/Portal\%2oSebrae/Anexos/Perfil\%2odo\%2oMEI\%202015. pdf $>$. Acesso em: 10 abr. 2017. 


\section{SERVIÇO BRASILEIRO DE APOIO ÀS MICRO E PEQUENAS EMPRESAS. Inadimplência} dos Microempreendedores Individuais. Brasília (DF), 2016b. Disponível em: <http://datasebrae.com.br/wp-content/uploads/2017/o4/Inadimpl\%C3\%AAncia-dos-microempreendedores-individuais.pdf $>$. Acesso em: 12 mar. 2018.

SERVIÇO BRASILEIRO DE APOIO ÀS MICRO E PEQUENAS EMPRESAS. Perfil do Microempreendedor Individual 2017. Brasília (DF), 2017a. Disponível em:

<http://datasebrae.com.br/wp-content/uploads/2017/o8/Perfil-do-MicroempreendedorIndividual_2017-v8.pdf> Acesso em: 12 mar. 2018.

SERVIÇO BRASILEIRO DE APOIO ÀS MICRO E PEQUENAS EMPRESAS. Quais as principais diferenças entre Microempreendedor Individual, Empresário Individual, Sociedade Limitada e Microempresa? Brasília (DF), 2017b. Disponível em: <http://www.sebraesc.com.br/leis/default.asp?vcdtexto=5813\&amp;>. Acesso em: 10 jul. 2017.

SILVA, Naiara de Moraes; TEIXEIRA, Solange Maria. Trabalho e "questão social" no capitalismo contemporâneo: a política social capitalista e o fetiche do microempreendedorismo individual no estado do Piauí. Revista Políticas Públicas, São Luís, v. 19, n. 2, p. 625-632, jul./dez. 2015.

TAVARES, Maria Augusta. Os fios (in)visíveis da produção: informalidade e precarização do trabalho no capitalismo contemporâneo. Outubro, São Paulo, n. 7, p. 49-6o, fev. 2002.

VALENTIM, Erika Cordeiro do Rêgo Barros; PERUZZO, Juliane Feix. A ideologia empreendedora: ocultamento da questão de classe e sua funcionalidade ao capital. Temporalis, Brasília (DF), n. 34, jul./dez. 2017.

Erika Cordeiro do Rêgo Barros VALENTIM. Participou da concepção, do delineamento e da redação do artigo.

Assistente Social. Mestre em Serviço Social pela Universidade Federal de Pernambuco. Assistente Social residente da Rede de Atenção Psicossocial (RAPS) do município de Recife (PE).

Juliane Feix PERUZZO. Participou da concepção, do delineamento e da redação do artigo. Assistente Social. Doutora em Serviço Social pela Pontifícia Universidade Católica do Rio Grande do Sul. Profa da Graduação e Pós-Graduação do Curso de Serviço Social da Universidade Federal de Pernambuco. 